\title{
SCHOOL SUBJECTS AS MATERIAL FOR TESTS OF MENTAL ABILITY. I
}

\author{
CLARA SCHMITT \\ Assistant, Department of Child-Study, Board of Education, Chicago
}

In several large cities the school child, because of his unfavorable reactions to the school situation, comes in for clinical diagnosis of mental and physical condition. Since it is the child's reaction to the school situation which is at fault, it is well to test him along the line of the special abilities which he is expected to develop under the conditions of the school situation. The school subjects may be made to form a series of tests which can be used from year to year to measure or check up the development of special abilities. The curriculum of the school forms a serial arrangement of accomplishments proceeding from the simplest subject-matter of the first grade to the complexities of the eighth grade. Such an arrangement of tests derived from the school subjects as forms a psychological serial arrangement from that which is simplest to that which is complex may be derived from the curriculum as it exists. The following series of tests and suggestions for the evaluation of the child's development with reference to the school curriculum has resulted from an examination of several hundred children considered by the school to be unfavorable in their reaction to the school situation, and comparison of them has been made with children considered normal with regard to their reaction to the school situation. The subjects chosen for this series of tests are those of reading, writing, and arithmetic. The tests pertaining to reading are discussed in this article.

\section{READING}

The most important accomplishment in the school life is that of reading. The child's progress throughout the school is dependent entirely upon his attaining it. Upon it depends his progress, to a large extent, in arithmetic and almost entirely in history and 
geography and other such subjects which consist of classified or organized groups of facts.

The accomplishment of the child in this subject may be arranged with reference to quantity and quality. A defective child may be deficient in one or both of these two characteristics of the reading accomplishment. He may be incapable of learning to recognize the words of the printed page; he may show himself capable of learning words only very slowly or of forgetting them quickly and easily. He may show himself capable of learning words with some facility in memorizing them, and so of becoming a good reader, but incapable of gaining ideas from the words which he reads. It is this latter characteristic which one is to understand as included in its various aspects under the term "quality."

The child may show an ability to recognize words from the printed page to a greater or less extent, but this recognition with the defective child consists, largely, merely of a mechanical type of visual memory which serves as a stimulus for its associated vocal prototype. The child who learns words in this way only is always dependent upon his teacher, since he can acquire for himself no new or unfamiliar word from the printed page. He can become somewhat independent of his teacher only if he learns phonetic values. Defective children are sometimes capable of acquiring very large visual vocabularies, but show themselves quite deficient in perceiving phonetic relationships. Children of the first grade may be expected to acquire the simplest phonetic elements of the English language. ${ }^{x}$ The child who can obtain a visual vocabulary with facility, who gains a perception of the simple phonetic values, and who learns to combine them correctly for the independent learning of new words is considered a favorable reactor so far as the subject of reading in the first grade of the public schools is concerned. The various steps from the early period of the reading accomplishment to its complex fulfilment are indicated as follows:

I. Quantity.-I. Knows no words: This is the condition of the average child when he enters school at six or seven years of age, and is one persisted in by the low type of defective child for several years. This low type of defective child shows himself incapable of

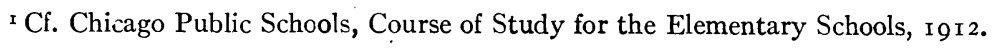


perceiving the fine differences which serve to distinguish one word from another on the printed page, though he is able to use spoken language. Some knowledge of the degree of his defectiveness may be gained when one knows the length of time in which he has persisted in this disability.

2. Can recognize a few unrelated words: This is the accomplishment of the average normal child after a few days spent in the school. It is a condition persisted in by many defective children sometimes for years. In such case, the defective child has learned a word here and a word there which has stuck in his memory, and he recognizes them wherever he sees them. He shows himself, however, incapable of gaining sufficient words to make his reading a consecutive process with regard to meaning. The words which he does learn bear, perhaps, no relation to the amount or type of teaching that has been given. The learning of them is largely a matter of chance, and just why certain words have been learned, and many others imparted at the same time in his instruction have been forgotten, cannot be determined.

3. Can read entire sentence in the first or some other reader: This step in its simplest form is attained by the child after a few weeks in school. The reader which he has in school-if because of being a defective he is placed in an ungraded room-compared with the number of years that the child has been in school is some measure of his defectiveness in learning to read.

4. Can read at sight any material such as newspaper, etc.: This is the highest grade which may be attained in the ability to read, with reference to quantity. It is attained by the normal child with the fifth grade. The phonetics which underlie the reading process is the great stumbling-block of the defective child. Seldom is one found who has this accomplishment. He may be able to learn a very few of the simplest combinations, such as consist of one or two consonants and a vowel. The normal child progresses in his knowledge of phonetic values to such an extent that he becomes independent of the teacher in so far as the illogical complexities of our English spelling permit. At the fourth grade the normal child is able to work out new and unfamiliar words with approximate phonetic correctness. 
II. Quality.--I. The defective child may be able to accomplish with reference to quantity in reading anything between the limits set above from the lowest to the highest stage of accomplishment. However great his accomplishment in the quantity of his reading, he is unable to read a new passage other than mechanically, that is, all he can do is to use a familiar popular phrase, parrot-like. This type of reading may be described as a straight line association between the visual and vocal centers. The child makes no, or few, other associations with the ideas gained from the printed page before him. The words or ideas which he reads do not relate themselves in his mind with anything else he has read, or with other experiences he has had, to the extent that a complex of related ideas is formed in his mind which he can reproduce orally or otherwise. He can reproduce few, if any, of the ideas which the page contains. Upon being asked what he has read about, he remains dumb or answers with merely a word or phrase contained in what he has read. This type of reading may be suspected from the monotonous tone with which it is delivered. An extreme example of this type was that of a girl of eleven, found in the second grade. She had attained the fourth step in quantity, and was very proficient in her rendering of phonetic values. She read a long paragraph, of which the following is the beginning sentence: "It was in the spring of the year 1826 about Io o'clock, when Mr. Amos Bliss, manager and one of the proprietors of the Northern Spectator, was in the garden behind his house planting potatoes," etc. This selection was taken from a Fifth Reader which she had never seen. She pondered over the unfamiliar words "spectator," "proprietors," and "manager," and pronounced them correctly, with very little loss of time. The other words in the selection were read with little or no hesitation. Upon being asked what she had read about, she made no reply; and when the question was repeated she finally said, "It was about a horse." The selection contained no reference to a horse, but the opposite page contained a picture of a horse. The normal child, when reading material which is not familiar to him must give much attention to spelling and deciphering unfamiliar words. He will often, because of this distraction, be unable to give the sense of the selection read. A judgment of the quality of the child's 
reading should, therefore, in every case, be deduced only from material which he reads with reasonable facility and which contains few if any unfamiliar words.

2. Appreciative: This type of reading is the opposite of the mechanical type just discussed. With this type there is usually expression of tone in reading which shows the child's understanding or appreciation of the selection read. Upon being questioned, he can tell in a sentence or more the essential elements of a selection. It is usually a sure sign that the reading has been appreciative if pleasure is shown. However, expression is not an infallible test. Defective children may be trained to read selections with expression, and if the circumstances of the training have been pleasant the child may incorporate these pleasant associations into the reading process itself, so that he seems to be enjoying the ideas derived from the selection. In such a case, however, he fails to read with expression or to reproduce the sense of the meaning when the same material is arranged in unfamiliar form.

3. Apperceptive: This is a grade of performance above the appreciative, in that there is a relating of what is read to a larger complex of knowledge or experience in addition to the reproducing of content. In this type of reading the child can reproduce orally without further prompting the essential details and can give an interpretation of a selection. Fables lend themselves readily to such an interpretive test. Defective children often can answer correctly any question asked about a selection read, but are unable to organize it for themselves and are unable to give an interpretation of its meaning when the material is of a literary type other than that of didactic narrative.

4. Initiative; reads voluntarily: Many children who attain the highest stage as relates to quantity in reading may at the same time really be able to gain so little from such abstractly represented ideas that they never voluntarily read for their own pleasure. Many children who have not yet gained the highest stage as relates to quantity still read voluntarily because of a desire to gain knowledge or to meet certain social demands. It is seldom that a defective child reads from any other motive than to please his teacher. 
RESULTS OF READING TESTS FOR NORMAL AND DEFECTIVE CHILDREN

Two selections to test ability in reading were given to seventeen children of each grade from the first to the sixth chosen from five public schools of Chicago. Three from each grade were chosen from four schools and five from another. These schools were situated in foreign-speaking districts. Of the eighty-five children tested, thirty-eight came from homes which were counted as English-speaking, since the mother was able to speak English. In the remaining forty-seven homes, according to the testimony of the children and the teachers who knew them, the mothers could not speak English.

The teachers were given the following directions for choosing the children for the test:

Select children who are average good readers for the grade; do not select the very best readers you have. Select them from that age of which you have most; that is, if you have more nine-year-old children than any other age select nine-year-old ones.

The first-grade teachers were asked to select only those who had begun school in September. The teachers consulted the record of ages upon entrance in September. The tests were given during the six weeks of May and June. The children of the first grade were, then, near the seventh birthday; the second grade were near the eighth; the third grade were near the ninth; the fourth grade were near the tenth, and the fifth grade were near the eleventh.

The defective children who were given the tests at the same time and in the same way were between the ages of ten and sixteen who had been in the special rooms for defective children for at least one year. Many of them had been in these rooms for several years. With one exception the rooms were situated in the schools in which the normal children were tested. There were five such rooms. Forty-six children of the eighty who constituted the membership of these rooms fell within the conditions chosen. None of them had uncorrected defects of sight or hearing.

The first of the selections chosen was the story of "The Fox and the Grapes." 


\section{The Fox AND THE GRAPES}

One day a fox went down the road.

"How hungry I am!" he said. "I wish I could find something to eat."

Just then he saw a grapevine. It had ripe grapes on it.

"Oh, how good those grapes look! I will have some," said the fox.

But he could not reach the grapes. They were too high on the vine.

He jumped high up in the air, but he could not get them.

At last he went away hungry.

The birds heard him say, "Those old grapes are sour.

They are not good for a fine fox like me."

But the birds knew better.

This selection was made in order to give each child something to read that he had been taught in school. The story is one of the lessons of the First Reader taught at the end of the first year. All but the first group of the first-grade children tested had read it. The general practice of the school with such stories as this is to read, recount, and discuss and in some instances dramatize the story. If the children had not all had an opportunity to recount the story individually they had heard some of their classmates do so and had joined in the discussion of it. All the defective children had had opportunity to hear it and read it and doubtless to recount it several times, since much attention is given to such work with the defective children. Each child had spent at least two years in the first grade before entering the special room.

The defective children were all mentally at least seven years of age according to the Binet scale. With the exception of the stamp-counting test with which three failed, all could pass all the tests of seven years of age. All could do the Thorndike $a$ test with no more than three errors. All could do the Healy-Fernald Test I, as well as the average of the first grade. With tests of greater complexity there was much variation.

The data recorded include time for reading the selection, errors of pronunciation, verbatim reproduction of the story, and the correctness or falseness of the interpretation of the motive of the fox in saying the grapes are sour. This last item was obtained by asking after the child had given his reproduction of the story, "Were the grapes sour ?" If the answer was "No," then "Why did he say so?" The interpretation was considered correct when the 
child indicated that the fox was disgruntled at not being able to get the grapes. The idea was not always expressed in words, but sometimes in an inflection of the voice in the answer, "Just because he couldn't get them." If the answer to the first question was "Yes," then the question was asked, "How did he know?" To this question there was sometimes an attempt to make an explanation such as that of one child, "He looked at them," but generally there was silence.

The reproduction was classed under the following heads, scant, adequate, and full. That reproduction was classed as scant which did not contain a sufficient number of the essential details to tell the story, or which had them so mixed or otherwise wrong that the story was not correctly rendered. An adequate reproduction contained enough detail to indicate the story, but with little or none of the embellishing details of dramatic setting. The full reproduction contained all or nearly all the items of the original story.

The two following reproductions were classed as scant.

"The fox couldn't reach the grapes, he went away hungry, the birds knew better."

"The fox was hungry, he wanted something to eat, so the birds said them grapes are not good, they are sour."

It should be remarked here that no reproduction was classed scant if the child could answer a series of questions which would bring out his understanding of the story, such as, "What did he try to get?" "What did he say?" etc.

The following is one of the poorest in the matter of detail of the reproduction classed as adequate:

"About" the fox, he was hungry, and he wanted some grapes to eat, they were too high and he could not get them and he said those grapes are sour."

The following is a full reproduction:

"One day the fox went down the road, he was very hungry, he said I wish I had something to eat, then he saw a grapevine, it had ripe grapes on it, how nice it looked, I will get some, but he could not get any, then he went away hungry, the birds heard him say, those grapes are sour, those grapes are not good for a fox, but the birds knew better." 
In recording mispronunciations those words which the child could not decipher in ten seconds were classed with the mispronounced. Words mispronounced in reading such as "then" for "they" were called to the child's attention with the question, "Is it 'then'?" If he pronounced it correctly the word was not classed with the mispronunciations. The time record for normal children includes time taken up in this way. For the defective children a time record was seldom of any significance because of the many corrections and helps necessary to get the child through the selection.

The first-grade children of the first school tested varied so widely from the other first-grade groups that their record could not be included in the averages. Their performance supported the assertion of the principal that this particular group of foreigners was very slow in learning to read. It is possible that their record would have been nearer the average if they had been tested last. The same backwardness in reading was evinced somewhat by the second grade of that school, but not sufficiently to make necessary their elimination from the averages. The third grade showed no variation.

Table XXXIV shows the data gained from selection I.

\section{TABLE XXXIV}

Data of Reading Test I

\begin{tabular}{|c|c|c|c|c|c|c|c|c|}
\hline \multirow{2}{*}{ Grade } & \multirow{2}{*}{$\begin{array}{c}\text { NUMBER } \\
\text { OF } \\
\text { ChILDREN }\end{array}$} & \multirow{2}{*}{$\underset{\text { TIME }}{\text { AVERAGE }}$} & \multirow{2}{*}{$\begin{array}{l}\text { AVERAGE } \\
\text { NUMBER } \\
\text { ERRORS }\end{array}$} & \multicolumn{3}{|c|}{ REPRODUCTION } & \multicolumn{2}{|c|}{ INTER PRETATION } \\
\hline & & & & Scant & Adequate & Full & + & - \\
\hline $\begin{array}{l}\text { I I } \ldots \ldots \\
\text { III } \ldots \ldots \\
\text { IIV } \ldots\end{array}$ & $\begin{array}{l}\text { I2 } \\
\mathrm{r} 7 \\
\mathrm{I} 7 \\
\mathrm{r} 7\end{array}$ & $\begin{array}{l}82^{\prime \prime} \\
62^{\prime \prime} \\
48^{\prime \prime} \\
48^{\prime \prime}\end{array}$ & $\begin{array}{l}5 \\
0 \\
0 \\
0\end{array}$ & $\begin{array}{l}3 \\
0 \\
0 \\
0\end{array}$ & $\begin{array}{l}9 \\
9 \\
4 \\
5\end{array}$ & $\begin{array}{r}0 \\
8 \\
\text { I } 3 \\
\text { I } 2\end{array}$ & $\begin{array}{r}6 \\
6 \\
\text { 1 } 3 \\
\text { I } 5\end{array}$ & $\begin{array}{r}6 \\
\text { I I } \\
4 \\
2\end{array}$ \\
\hline
\end{tabular}

The time average for the first grade of Table XXXIV had a range as follows: 2 took between two and three minutes to read the selection; 6 between one and two minutes; 3 less than one minute. The error average was made up of one child's 5 errors and 2 other errors made by two children. 
The time average for the second grade ranged: I between two and three minutes; 4 between one and two minutes; 7 less than one minute. There was little variation in the time of the third and fourth grades.

It is rather significant of the small child's ability to understand the point of the fable type of story that though all these children had been taught this story and had discussed it more or less, it is at the third grade that it is understood. The children of the first and second grades who gave correct interpretation probably only reproduced their teaching.

The errors in pronunciation made by the normal children in this and the second reading test were always in favor of a word which had considerable visual or phonetic resemblance to the correct word. The errors made by the defective children with the first selection which was perfectly familiar to them in content, at least, were absurd so far as visual or phonetic values were concerned, but were calculated to fill in the context. The defective child reads, for instance, that the fox saw a vine with berries on it. Because of the great prevalence of this type of variation the performance of the defective group cannot be compared with that of the normal. Another type of comparison will be made below.

The second selection was chosen because of its unfamiliarity, its wide range of verbal difficulty, and simplicity of content, which at the same time possessed a definite unity. It was taken from p. I77 of Jones's Fifth Reader. This reader is not used in the schools, and probably had never been seen by any of the children who read the selection. Since the verbal expression is rather complex and the words used are not those of the ordinary child's everyday vocabulary, it was desirable to keep the content-matter simple, that not too many difficulties would confront the child at the same time. The paragraph selected was:

It was a fine spring morning in the year I 826 about ten o'clock when $\mathrm{Mr}$. Amos Bliss, the manager and one of the proprietors of the Northern Spectator, might have been seen in the garden behind his house planting potatoes. $\mathrm{He}$ heard the gate open behind him, and, without turning or looking around, became dimly conscious of the presence of a boy. But the boys of country villages go into whosesoever garden their wandering fancy impels them, and supposing 
this boy to be one of his own neighbors, Mr. Bliss continued his work and quickly forgot that he was not alone.

The same data as for the first test were recorded, except that there is no interpretation for this one.

Following is an example of a reproduction classed as adequate:

"A man was planting potatoes in his back yard and a boy came in and he thought it was one of his neighbor boys and he didn't pay any attention to him and forgot he wasn't alone."

The following reproduction was classed as full:

"Mr. Bliss was planting potatoes behind his house, he looked up suddenly and there was a boy coming in his yard, but in that country the boys go whereever their fancy impels them and he thought it was one of his neighbors and kept on with his work and after awhile he forgot that he was not alone."

No child grasped the significance of the title, "manager and one of the proprietors of the Northern Spectator."

Table XXXV shows the data of the second selection.

\section{TABLE XXXV}

Data for Reading, Test II

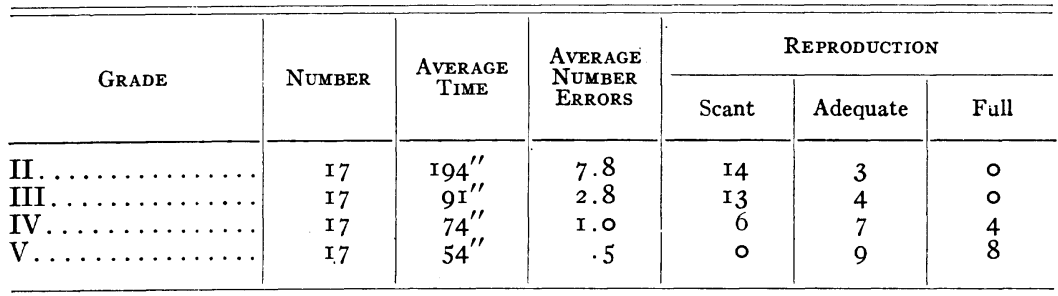

The words most frequently mispronounced were, "manager," "proprietors," "Northern," "Spectator," "conscious," "whosesoever," "impels," "continued." The mistakes of the normal children consist, for the most part, of misplaced accent, the omission of an obscure syllable in long words, or giving a different phonetic value than is the right one for the word in which the letter is found. Thus "manager" becomes "manager"; "proprietors" becomes "prop'rietors," or "propetors," etc. 


\section{RESULTS OF READING TESTS FOR DEFECTIVE CHILDREN}

The reading of the defective children presents such irregular characteristics that averages which would present any meaning are difficult to obtain. The children tested had been much drilled in the story of the Fox and the Grapes. Nevertheless 24 of the 46 could read it with less facility than the first-grade children. They made many errors of the absurd type discussed above. Their reading consisted of some unerring recognition of words and more or less filling-in to supply a remembered context. Nine of the defectives could give only a scant account of the story and an incorrect interpretation.

Twelve defective children were graded as equal to the first-grade child in reading ability. Ten were graded equal to the secondgrade child in ability as regards the mechanical and qualitative aspects of the second reading test. Two of the defectives of the second grade could give an adequate account of the matter read. One of these children was ten years of age and by reason of this test and others was reclassified on his record sheet as only backward and returned to the regular grades of the school. The other, twelve years of age, was so deficient in other tests that he was retained in the special room.

Table XXXV shows that it is only with the fourth grade that sufficient mechanical skill in reading has been attained to admit of sufficient attention to content to give an adequate reproduction of an unfamiliar selection. With the fifth grade, such skill has become general. 